\title{
A POESIA DE JURANDYR BEZERRA: ORGANIZAÇÃO DOS MANUSCRITOS INÉDITOS DE UM POETA QUASE ESQUECIDO
}

Paulo Vieira ${ }^{1}$

\begin{abstract}
RESUMO
O poeta Jurandyr Bezerra, nascido em Belém do Pará em 1928, e radicado no Rio de Janeiro de 1960 até seu falecimento em 2012, publicou apenas um livro, Os limites do pássaro, em 1993. Jurandyr é o menos conhecido dentre os poetas modernos do Pará que consolidaram obras ao longo da segunda metade do século XX. Ainda assim, mereceu a atenção de leitores como Carlos Drummond de Andrade e Antônio Olinto que, em 1958, premiaram-lhe. No arquivo do paraense, permaneceram oito conjuntos de poemas inéditos - As águas de Mara, A lâmina convexa, Configurações, Superfície, O rio da minha aldeia, O signo transverso, A rosa de Jericó e outras notícias da morte e Sombra submersa: recordações da Amazônia -, manuscritos em que se distinguem os trajetos do processo criativo. O presente artigo apresenta resultados do processo de classificação e organização dos manuscritos e análise de poema, realizado no intuito de dar mostra da relevância da poesia inédita de um significativo poeta brasileiro do século XX, praticamente desconhecido.
\end{abstract}

Palavras-chave: Jurandyr Bezerra. Manuscritos. Poesia inédita.

\begin{abstract}
The poet Jurandyr Bezerra, born in Belém do Pará in 1928 and living in Rio de Janeiro from 1960 until his death in 2012, published only one book, Os limites do pássaro, in 1993. Jurandyr is the least known among modern poets of the Pará that consolidated works throughout the second half of the twentieth century. Still, it received the attention of readers such as Carlos Drummond de Andrade and Antônio Olinto who, in 1958, awarded him. In the paraense archive, eight sets of unpublished poems remained - As águas de Mara, A lâmina convexa, Configurações, Superfície, O rio da minha aldeia, O signo transverso, A rosa de Jericó e outras notícias da morte e Sombra submersa: recordações da Amazônia - manuscripts distinguishing the paths of the creative process. This paper presents results of the process of classification and organization of manuscripts and poem analysis, designed to show the relevance of unpublished poetry by a significant Brazilian poet of the twentieth century, practically unknown.
\end{abstract}

Keywords: Jurandyr Bezerra. Manuscripts. Unpublished poetry.

Submetido em: 19.10 .2019

Aprovado em: 23.11.2019

\section{INTRODUÇÃO}

Em pesquisa recente abordamos a importância cultural da capital do Pará Vieira (2017), ao situar o ambiente do célebre poeta paraense Max Martins, pois Belém possui, de fato, uma história extremante profícua na produção de literatura, poesia, música,

\footnotetext{
${ }^{1}$ Professor Doutor em Literatura, Faculdade de Etnodiversidade, Universidade Federal do Pará - Campus Altamira. E-mail: paulorvieira@ufpa.br
} 
historiografia, antropologia, folclore, filosofia e arte. Desde o início da colonização (1616)², ligado diretamente à coroa portuguesa, o Pará tornou-se um polo regional de populações de referência na Amazônia. Somado a isso, a promoção da arte, o acúmulo cultural e a arquitetura da cidade - única e exuberante, com suas igrejas, capelas, solares, palácios, teatros - foram largamente favorecidos na transição do século XIX ao XX, período conhecido como a "belle époque"3 amazônica, devido ao enriquecimento da região por meio da explosiva exportação do látex, a goma elástica, matéria-prima da fabricação da borracha.

Conforme nos mostra Benedito Nunes, no livro De Marajó ao arquivo - breve panorama da cultura no Pará, esse fato "beneficiou, e muito, o já existente centralismo da cidade de Belém, tanto estético, do ponto de vista da paisagem, quanto comercial [...] e também cultural [...]" (2012, p. 47). A música, o teatro, a literatura e as artes locais ganhavam seus espaços e se consolidavam, enquanto a intelectualidade paraense se deleitava com espetáculos e exposições no imponente teatro da Paz.

Todavia, Antonio Candido ensina que a relativamente jovem história da literatura brasileira mostra que, desde suas primeiras manifestações no Brasil colônia, passando pela configuração de um "sistema literário" até atingir a consolidação desse sistema (2004, p. 14), os centros geográficos aglutinadores dos artistas que fizeram essa história foram, em princípio, a Bahia, depois Minas Gerais, Rio de Janeiro e São Paulo. Ao que, naturalmente, seguiu-se o aparecimento dos escritores de outras regiões, como o Nordeste e o Norte. Considerando a extensão continental do país, a ativação da vida artística das regiões mais distantes veio mais tarde, ou não foi plenamente conhecida no momento de sua eclosão; como foi o caso de Belém.

Transcorrido todo o século XX, hoje, no tocante aos estudos da crítica, a literatura do Pará ainda não teve a sua história devidamente situada no panorama da produção nacional. Sabe-se que no Norte, um dos primeiros escritores a despertar interesse foi o prosador Inglês de Souza (1853-1918), que expôs no Naturalismo os conflitos morais e sociais da imensa região pouco povoada na época. Mas houve outros, José Veríssimo, Peregrino Júnior, Osvaldo Orico, Eneida de Moraes, Abguar Bastos, além dos dois últimos grandes romancistas do Pará, Dalcídio Jurandir e Haroldo Maranhão.

Ainda quanto à história da literatura paraense, verifica-se que o desenvolvimento do Modernismo em Belém, ocorre a partir de meados de 1920. Na poesia, os principais autores

\footnotetext{
${ }^{2}$ Ver: SALLES, Vicente. Memorial da Cabanagem. Belém: Cejup, 1992.

${ }^{3}$ Ver: SARGES, Maria Nazaré. Riquezas produzidas na belle époque: Belém do Pará (1870- 1912). Belém: Paka - Tatu, Coleção Açaí, 2002.
} 
da primeira metade do século passado, Bruno de Menezes (1893-1963), Antônio Tavernard (1908-1936) e Paulo Plínio Abreu (1921-1959) - cujas obras, carentes de fortuna crítica, foram poucas vezes editadas - atualmente flutuam à deriva no rico e diverso, mas pouco estudado, quadro da literatura do Pará.

Com efeito, ainda na primeira metade do século XX, em 1931, o poeta negro e anarquista Bruno de Menezes, o mais destacado do período, escreveu o livro Batuque, poesia que resuma - como nos mostra a referência do título a tambores - o candomblé, em Belém chamado macumba. "Poesia negra", de incorporação da natureza local, de metáforas e traços sensuais, Batuque merecia ser posicionado junto das obras de referência do Modernismo nacional, escritas no mesmo período, como a rapsódia Macunaíma (1928), de Mário de Andrade e o poema Cobra Norato (1931), de Raul Bopp.

Voltando a Antonio Candido, sabemos que entre 1880 e 1890, com a influência portuguesa sobre a literatura produzida no Brasil já bastante lateral, e sob a égide de nova vertente, a influência francesa, surgiram sucessivamente o Simbolismo e o Parnasianismo nos meios artísticos dos grandes centros (2004, p. 74). E já nos dois primeiros decênios do século XX a literatura brasileira está consolidada e amadurecida, não havendo mais produções totalmente isoladas, multiplicou-se o número de escritores e definiu-se uma tradição local.

Ainda assim, em Belém, o isolamento geográfico - grave àquela época de transporte e comunicações extremamente limitados - fez com que só vinte anos após a revolução estética iniciada com a Semana de Arte Moderna, a poética modernista, já uma herança jacente dos revolucionários de 22, começasse a ser absorvida pela geração à qual os novos escritores do Pará se vinculavam, em uma espécie de "modernismo tardio". Benedito Nunes apresenta a geração posterior a de Bruno de Menezes, onde destaca, na poesia, "Jurandyr Bezerra, Alonso Rocha, Max Martins, Cauby Cruz e Mário Faustino” como “[...] os jovens poetas em ascensão entre os anos de 1950 e 1960" (2012, p. 53).

Deste ponto em diante, quero lançar luz sobre Jurandyr Bezerra (Belém, 1928 - Rio de Janeiro, 2012), o primeiro dos nomes elencados por Benedito Nunes. Tendo publicado apenas um livro, Os limites do pássaro ${ }^{4}$, em 1993, Jurandyr é o mais inédito e o menos conhecido dentre os poetas modernos do Pará que consolidaram obras ao longo da segunda metade do século XX.

\footnotetext{
${ }^{4}$ BEZERRA, Jurandyr. Os limites do pássaro. Belém: Edições Cejup. 1993.
} 
Homem tímido, o envolvimento do poeta com a literatura começou na juventude. No ano de 1943, em Belém, ao lado de Alonso Rocha e Max Martins, Jurandyr, então com 15 anos, editou a revista manuscrita Amazônia. Números com exemplar único, que passeava de mão em mão entre os admiradores e os integrantes da recém fundada Academia dos Novos, grupo reunindo mais de uma dezena de iniciantes em literatura, no qual, além dos poetas acima citados, estavam o crítico e filósofo Benedito Nunes e o romancista Haroldo Maranhão.

A formação, em 1942, da Academia dos Novos serviu como um primeiro atar dos laços afetivos que, além de garantir o diálogo do grupo nos assuntos literários naquele momento, perduraram por toda a vida. A circulação de poemas em revistas, ou em manuscritos e impressos avulsos, a partir de 1940 e de maneira artesanal, bem como a criação da Academia contribuíram para formar os jovens interlocutores da geração literária ascendente em Belém, da qual Jurandyr Bezerra se ausentaria fisicamente no princípio dos anos 1960, por força de sua mudança para o Rio, onde, até o final da vida, não se ligou a qualquer outro grupo literário. Leonam Cruz, amigo de Jurandyr desde a juventude e também integrante da Academia dos Novos, rememora, na orelha de Os limites do pássaro, a sagração da literatura e da amizade entre aqueles jovens da Belém dos anos 1940:

\begin{abstract}
Estava, assim, marcada a nossa ligação irreparável e indelével, porque tínhamos um ideal comum e inevitável na literatura. Ficamos unidos na Academia dos Novos e passamos a ter, em nossa frente, os mesmos caminhos, quase nada nos separando. Entre os nossos deuses escolhemos a lua, e vivíamos, quase sempre, até alta madrugada, nas esquinas da cidade, num convívio permanente que parecia eterno, com o nosso sonho de poesia. ${ }^{5}$
\end{abstract}

Considerando o comportamento tímido e quieto, a mudança de cidade, e o quase total ineditismo da poesia dele, deve-se dizer que, na atualidade, mesmo em Belém, Jurandyr Bezerra é autor de obra praticamente desconhecida do público, inclusive nos meios literários daquela cidade.

Ainda na capital do Pará, na década de 1940, a fundação e direção do Suplemento Literário de A Folha do Norte, por Haroldo Maranhão, um dos confrades da Academia dos Novos, ajudou a projetar aqueles jovens poetas (MAUÉS, 2012). O tabloide dominical, que durou de 1946 a 1951, era completamente antiprovinciano, pois captava manifestações da melhor e mais recente produção literária do Brasil e do exterior.

A esse Suplemento Literário convergiam poemas recém-escritos por Carlos Drummond de Andrade, Cecília Meireles, Manuel Bandeira, entre outros, textos que se

\footnotetext{
${ }^{5}$ CRUZ, Leonam. Orelha, In: BEZERRA, Jurandyr. Os limites do pássaro. Belém: Edições Cejup. 1993.
} 
alternavam com a poesia de paraenses mais velhos como Bruno de Menezes, Ruy Barata e Paulo Plínio Abreu, que os "Novos" começavam a conhecer e a admirar. Assim, Jurandyr Bezerra principia a publicar no encarte de domingo alguns de seus primeiros poemas.

Em 1946, com 18 anos, Jurandyr foi eleito para a Academia Paraense de Letras, apresentando trabalhos inéditos de poesia. No Pará, foi professor de Língua Portuguesa em cursos de nível ginasial e jornalista - entre 1947 e 1961 - na Folha do Norte e na Folha Vespertina. Havia assumido, em 1961, as funções de secretário da Folha Vespertina quando foi convidado pelo Ministro da Saúde do Governo Jânio Quadros, o depois Senador pelo Pará, Cattete Pinheiro, para exercer um cargo, no Rio de Janeiro, naquele ministério.

$\mathrm{Na}$ Zona Norte carioca Jurandyr Bezerra se estabeleceu, criou seus cinco filhos, leu, escreveu poesia e viveu junto da família até o seu falecimento em 2012. No pequeno apartamento, Jurandyr reservou o menor cômodo para seu modesto escritório, onde guardava meio século de manuscritos. $\mathrm{O}$ arquivo preserva manuscritos da poesia inédita de Jurandyr Bezerra. São oito pequenos conjuntos de inéditos escritos entre meados de 1960 e 2011, por ele nomeados assim: As águas de Mara, A lâmina convexa, Configurações, Superfície, O rio da minha aldeia, O signo transverso, A rosa de Jericó e outras notícias da morte e Sombra submersa: recordações da Amazônia. Apresentam-se como digitoscritos em folhas de papel A4, cada conjunto preso por um clipe de metal, havendo versões de cada um dos conjuntos.

A maioria dos textos mostra rasuras expressivas e advertências/lembretes a caneta esferográfica. No arquivo encontram-se também cerca de trinta páginas soltas - manuscritos autógrafos - que são versões de poemas nos oito conjuntos referidos, ou ainda títulos fora dessas reuniões. Deve-se dizer ainda sobre o arquivo de Jurandyr Bezerra, que após o falecimento do poeta em meados de 2012, a maior parte do material composta de recortes de jornais, revistas, cadernos de estudos, crônicas, correspondências, manuscritos autógrafos, digitoscritos e datiloscritos foi perdida, preservando-se apenas a parte do arquivo que mais diretamente dizia respeito à obra poética de Bezerra em fase final de elaboração, principalmente as versões dos digitoscritos que perfazem os oito conjuntos de poemas.

Visando a edição da poesia inédita de Jurandyr, desde meados de 2017 iniciamos a classificação à luz da arquivística, da codicologia e da crítica genética dos oito dossiês dos manuscritos correspondentes aos oito conjuntos de inéditos de Jurandyr Bezerra; analisando 
as rasuras correspondentes às etapas da criação ali presentes ${ }^{6}$. Procedendo de modo a buscar compreender a fusão das rasuras ao texto impresso, o que torna o manuscrito em uma nova versão.

Assim, se pretendeu captar o itinerário da criação dos poemas pertencentes aos oito conjuntos de poemas inéditos de Jurandyr, estabelecer o texto de cada conjunto, possivelmente de acordo com a última versão nos manuscritos, procedendo à transcrição e à redação das notas necessárias. Este artigo tem por objetivo dar mostra do processo de organização dos conjuntos e análise de poema.

\section{METODOLOGIA DE CLASSIFICAÇÃO E ORGANIZAÇÃO DOS MANUSCRITOS DE POESIA}

O material desta pesquisa é a obra inédita do poeta paraense Jurandyr Bezerra, nos títulos citados que a constituem. O método reporta-se ao campo da arquivística, da codicologia e da crítica genética concernindo à organização dos manuscritos do poeta. Assim, conforme ensina Cecília Almeida Salles, a observação do material, ou seja, dos manuscritos dos conjuntos, conduz a análise pelos "labirintos criativos" do poeta em sua escritura (2008, p. 65).

Cabe aventar que nas últimas décadas do século XX, o advento da crítica genética, suscitando a pesquisa da gênese literária que passou a oferecer, segundo Louis Hay, um objeto novo - o manuscrito - e uma problemática - o estudo da produção intelectual - que era comum a outras disciplinas (2003, p. 66). Esses novos tempos, que se estendem até a atualidade, serviram à valorização do manuscrito como objeto de pesquisa importante à compreensão e análise de certos aspectos da obra de arte antes praticamente insondáveis.

Assim, no centro desta pesquisa está a produção poética inédita de Jurandyr Bezerra, a qual soma os títulos citados - As águas de Mara, A lâmina convexa, Configurações, Superfície, $O$ rio da minha aldeia, $O$ signo transverso, A rosa de Jericó e outras notícias da morte e Sombra submersa: recordações da Amazônia. As oito coleções de poemas inéditos, digitoscritos, a maioria sem encadernação, mostram-se presas, cada qual por clipes ou grampos de metal. Nos manuscritos verificam-se rasuras, geralmente nas margens, traçadas a caneta esferográfica preta, azul e vermelha, mas também a lápis frequentemente.

\footnotetext{
${ }^{6}$ O Projeto de pesquisa "Edição da poesia completa de Jurandyr Bezerra e organização dos manuscritos do poeta", foi desenvolvido na UFPa, Campus Altamira, no período de 01 de agosto de 2017 a 31 de julho de 2019. Portaria 103/2017.
} 
Mesmo inéditos, os dois primeiros títulos, As águas de Mara e A lâmina convexa foram premiados em certames nacionais - Menção honrosa no concurso de Poesia Ruth Scott, do Sindicato dos escritores do Rio de Janeiro, em 1993, e menção especial no prêmio Ribeiro Couto, da União Brasileira de Escritores do Rio de Janeiro, em 1997, respectivamente. Apesar da sagração desses dois conjuntos, o autor não considerava finalizados os poemas e frequentemente os retomava, rasurando-os e instituindo, assim, novas etapas de redação. Os fólios desses conjuntos, assim como dos outros seis acumulam rasuras de vário naipe substituições, acréscimos e deslocamentos.

\section{MÉTODO DE ORGANIZAÇÃO DOS MANUSCRITOS DE JURANDYR BEZERRA}

O trabalho de classificação e organização da obra manuscrita do poeta Jurandyr Bezerra é lento, pois é preciso observar os manuscritos com o devido tempo e vagar para desnudar alguma trilha ou fio condutor, no que concerne à organização dos materiais, que antes encontravam-se reunidos de forma aleatória, ainda sem um tratamento necessário à sua compreensão para edição. Essa primeira aproximação e organização, nos oferece a possibilidade de melhor compreender o que, em crítica genética, é chamado de "caminhos do processo criativo", trabalho fundamental e basilar para a reunião acertada da edição e para a preservação de manuscritos.

Todavia, deve-se ainda discutir, acompanhando Cecilia Almeida Salles, o próprio conceito de manuscrito. Para a pesquisadora o termo já não é utilizado com o restrito sentido de "escrito à mão". Em sua avaliação, "Dependendo do escritor podíamos deparar com documentos escritos à máquina, à mão, digitados no computador ou provas de impressão, que receberam alterações por parte do autor" (2009, p. 21). Nesta descrição se insere a maioria dos digitoscritos deixados por Jurandyr, digitados ao computador, impressos em geral dois a três pares de vezes e frequentemente retrabalhados, retocados a caneta ou lápis. Esse estágio da produção inédita do poeta, por muitos lados, ajudou-nos a iniciar a organização do material, seguindo alguma luz das suas intenções quanto aos rumos do que planejava ao conjunto.

Assim, nosso passo primeiro, ulterior ao início das análises críticas, foi a criação de Lotes de Manuscritos numerados, conforme correlações internas, ligações objetivas (como poemas reunidos por clips ou grampos), títulos de conjuntos, datações, ou páginas soltas 
datadas e não datadas. A seguir os resultados da organização inicial dos lotes de manuscritos inéditos do poeta Jurandyr Bezerra:

\subsection{ORGANIZANDO O MATERIAL EM LOTES}

No que se refere ao estudo de manuscritos, é preciso ter em conta que observar a comunicação interna do material inédito é fundamental à sua compreensão. A organização dos lotes apresentados aqui resulta desse tipo de análise detida:

Lote 1 - As águas de Mara. Esses poemas em diferentes versões nos tomaram bastante tempo à compreensão de como deveria ser seu ordenamento, pois se tratava do lote com poemas mais aleatórios dentre os conjuntos cultivados pelo poeta, com papéis soltos, sem qualquer numeração ou datas. Deve-se dizer que "As águas de Mara", é o poema mais representativo do conjunto, assim procedemos em relação ao demais lotes, nomeando-os, sempre que possível, com o título de um poema que nos parecesse fundamental ao conjunto.

Todavia, levando em conta a complexidade da tarefa de entender o que pensou o autor e como proceder para aproximar das ideias originais um conjunto de poemas para edição, cabe aludir ao que nos ensina o renomado pesquisador francês Philippe Lejeune, "Muita gente ronda em torno da poesia para que ela conte sua história e seja obrigada a confessar-se: o próprio poeta por vezes, seus leitores e exegetas frequentemente: mas a poesia escapa da autobiografia e foge na ponta dos pés" (2008, p. 99). Assim, organizar os manuscritos de Jurandyr Bezerra é ainda apreciar os desenlaces da poesia, buscando ordenar forças que em si mesmas já conhecem seus caminhos e seus descaminhos.

Lote 2 - A lâmina convexa. O lote possuía uma versão de cada um de seus poemas e estava unido por um clip de metal que causou manchas devido a oxidação, na capa do lote existe uma nota: - Menção Especial do "Prêmio Ribeiro Couto" (Concurso Nacional), da União Brasileira de Escritores (UBE - Rio) - 1997. Anotou-se que os poemas estão numerados, a caneta, no lado direito inferior do texto, do número 70 ao 88 . Este lote é o mais extenso contendo dezesseis poemas, em diferentes versões, dispostos na seguinte ordem de títulos: "Origens", "A metáfora", "A manhã", "Imagem interior", "A seda", "Memória", "Há", "Por quê?", "Poema da não existência", "Tatuagem", "Poema para os seios da amada", "Depois", "Elegia”, "Distância", "Sempre" e "Perda".

Com efeito, cabe indagar, se esse conjunto fora submetido pelo autor à disputa de um prêmio literário, o que sugere o término de sua elaboração, por que não foi, nas décadas seguintes, publicado como livro? Nesse sentido, Louis Hay reitera que ao leitor ou pesquisador não cabe o espaço de partícipe de nenhum trabalho, de nenhuma decisão, nem da 
incerteza do fim ou conclusão de uma obra, "É ainda o escritor que, sozinho habita o tempo da escritura: o da origem, o do livro antes do livro, o tempo dos possíveis, do acabamento longo ou breve, incerto ou perfeito". (2007, p. 13).

Lote 3 - Configurações. Nesse lote encontramos três grupos de poemas onde muitos se repetem em versões. Desses, o primeiro possui somente dois poemas, "Domingo" e "Vazio", impressos em papéis bastante degradados pela ação do tempo. Ficamos refletindo sobre qual grupo seria o mais atual. Optamos pelo segundo grupo, por apresentar a construção mais elaborada dos poemas e, até o momento, estamos convencidos de se tratar da versão final, onde se destaca "Quatro poemas para Lucidea".

O segundo grupo apresenta dois poemas que no terceiro grupo são representados por marcadores que os indicam, enumerados a caneta no lado direito inferior do texto, do número 91 ao 101, grafado em contracapa o seguinte texto: “A caixa miúda da caixa miúda, Apaixonou-se por si mesma também, E começou a gerar, Uma outra caixa miúda, E assim foi ao infinito. Vasko Popa (Trad. de Aleksandar Janovic)”, nesse grupo contamos onze poemas, ao todo, distribuídos na seguinte ordem: "Quatro poemas para Lucidea", "Fragmentos para uma canção de ninar", “Tempo", “A paisagem”, "Vazio”, "Infância”, "Poema para Eugene Guillevic", "Poema sem título", “Arcos", "Natureza morta" e "Domingo".

Considerando as referências a autores (Janovic, Guillevic), gesto frequente nos poemas de Bezerra, verificamos, ao investigar a pequena biblioteca pessoal dele, que o poeta era leitor e estudioso autodidata da literatura. Jurandyr lia e relia, continuadamente, os autores brasileiros, principalmente, a poesia de Olavo Bilac, Vicente de Carvalho, Sousândrade, Mário e Oswald de Andrade, Dante Milano, Jorge de Lima, Murilo Mendes, Carlos Drummond de Andrade, Manuel Bandeira, Cecilia Meireles, João Cabral de Melo Neto, Ferreira Gullar, Bruno de Menezes, Mário Faustino e Max Martins.

Dentre os estrangeiros, estudou detidamente, como apontam as notas de margens e fichamentos nos livros da sua biblioteca, os poetas Homero, Dante, William Blake, Shakespeare, Rainer Maria Rilke, Eugenio Montale, Saint-John Perse, Jules Laforgue, W. B. Yeats, Charles Baudelaire, Georg Trakl, Paul Celan e outros.

Dedicou-se também ao estudo da teoria e da crítica literária; a biblioteca guarda obras de autores como Ezra Pound, Roman Jakobson, Tzvetan Todorov, Octávio Paz e Umberto Eco; como Otto Maria Carpeaux, Benedito Nunes, Massaud Moisés, Alfredo Bosi, Telê 
Ancona Lopez, Salete de Almeida Cara, Gilberto Mendonça Teles, Segismundo Spina e Jacob Guinsburg.

Os interesses do leitor Jurandyr Bezerra passavam ainda pela Bíblia Sagrada e por mitologias - gregas, romanas, dinamarquesas, romenas, polonesas, russas e amazônicas. O poeta estudou, em casa, nos livros e nos materiais audiovisuais que adquiria, pelo menos seis línguas - grego, italiano, francês, polonês, romeno e espanhol. Encontrei, na biblioteca dele, como marginália apensa ao volume "Os gregos e seu idioma", notas do estudo de palavras e das letras do alfabeto.

Lote 4 - Superfície. A primeira grande questão referente a esse lote de manuscritos era que existem duas versões do poema "Superfície", a primeira, que estava disposta sobre a segunda, apresentava uma coloração amarelada, nitidamente mais envelhecida. Digitada na fonte Times New Roman, distribuída em duas laudas, diferente da segunda versão, onde o foi ajustado em uma lauda apenas. Existem alterações, uma no primeiro verso do poema, onde "bem-aventurados" foi substituído por "mal-aventurados", na segunda versão.

Conforme a organização do lote, temos atualmente onze poemas dispostos na seguinte ordem: "Superfície", "Tempo adverbial", "Canto II", "Canto XII”, “Canto XIII”, "Do verbo navegante", "Flor silvestre", "Sensibilidade da sombra", "Canção da noite em si”, “A escola temp(l)o de Íris" e "Quase poemas”. Existe ainda uma página de contracapa com o título "Poemas interiores".

Lote 5 - O rio da minha aldeia. O conjunto possui um grupo de poemas dispostos na seguinte ordem: "Introdução do poema (O rio)"; "Os sonhos do poeta”, "sonho VI"; "O corpo do rio e suas águas", “Ondas", "Preamar", "Baixa-mar", “Inundação", “Foz”. Enumerados a caneta no lado direito inferior do texto, do número 119 ao 127 , além do poema "O rio" em uma versão anterior que tinha por título "O rio Amazonas".

Lote 6 - O signo transverso. Esta coleção possui oito poemas enumerados a caneta no lado direito inferior do texto, do número 137 ao 143, dispostos na seguinte ordem: "Noturno", "Mona Lisa", "Diferença", "Sinas", “A chuva", "O canto da alma ausente”, "Diagnóstico", "O penúltimo poema". O poema na página 142 traz em seu último verso uma rasura feita a caneta para trocar a palavra "não" por "nem”, junto ao acréscimo de um ponto de interrogação e outra rasura para encobrir (excluir) um possível último verso.

Lote 7 - A rosa de Jericó. Este conjunto, até o momento, é composto por dois poemas, o primeiro com o título "Espelho", e o segundo "Murilo Mendes: criador de luas", enumerados a caneta no lado direito inferior do texto, do número 145 ao 148 . O poema mais extenso de Bezerra até aqui é "Murilo Mendes: criador de luas", que soma três laudas. Este 
poema tem uma rasura feita a caneta na oitava estrofe para trocar "E" por "e" na palavra “espandongada", no poema também constam palavras com formatação em itálico.

Lote 8 - Sombra submersa. A capa deste lote possui, entre aspas, no lado inferior direito do título o subtítulo "Recordações amazônicas" e os poemas estão enumerados a caneta no lado direito inferior do texto, do número 150 ao 153. Apresenta apenas dois poemas, "Carta aberta de amor e saudade para Amazônia" e "Mururé". O primeiro poema possui um glossário para consulta do leitor.

Lote 9 - Biografia. Criamos este lote para reunir materiais como cartas, recortes de jornais, convites, bilhetes, fortuna crítica, entre outros materiais que, não sendo poemas, ajudam na compreensão da biografia do autor e na sua composição para a poesia completa de Jurandyr. Nesse lote estão cartas de concursos em que seus poemas foram premiados, fotos de cerimônias em que o poeta recebeu láureas, bilhetes e cópias de editais impressos. Nessa chave, nos concentramos na ideia de que a vida e as ações do autor podem explicar certos sentidos de marcados na ordem interna da obra, assim aventa Lejeune, "Confrontamos o que vimos com o que lemos, tentamos imaginar o que teremos para ler segundo o que vimos. $\mathrm{O}$ autor nos leva ao livro e o livro ao autor”. (2008, p. 196).

Lote 10 - Inéditos. O último lote foi destinado aos manuscritos inéditos "soltos" completamente manuscritos, ou seja, sem haver versões digitadas ao computador, digitoscritos, ou a máquina de escrever, datiloscritos -, cuja organização consta de um processo longo de compreensão da gênese dos poemas (rasuras, substituições, rearranjos) e suas posições no conjunto da obra. Deve-se dizer ainda, nesse sentido, acompanhando novamente Cecilia Salles que "O ato criador como uma permanente apreensão de conhecimento é, portanto, um processo de experimentação no tempo.” (2009, p. 133).

\subsection{ANÁLISE DE POEMA MANUSCRITO}

No tocante à análise dos manuscritos, o poema "Carta para Fernando Pessoa" (Figura 1), que integra a coleção Superfície, simula por meio do jogo poético o envio de uma missiva do poeta paraense ao português Fernando Pessoa. O ambiente melancólico atravessa as estrofes, onde Jurandyr põe em discussão, numa espécie de balanço íntimo, o trabalho da poesia, qual seja, o próprio poetar.

Já no título, o poeta inclui a palavra "dúvida", para em seguida suprimi-la. Dúvida que diz respeito a célebre indagação de Pessoa, "Valeu a pena?", em versos que encimam, como 
epígrafe, o poema em processo. Se o português se referia à vida, o paraense segue a mesma chave, embora convertendo poesia em vida, vida em poesia.

Jurandyr escreve a estrofe final, "Fernando Pessoa, / amena / não foi nossa vida, e a fuga / nem sei se valeu a pena”, enfocando no eu, no biográfico, talvez na vida cotidiana, para em seguida rasurar a estrofe, moldando-a numa inútil tentativa de apagamento desse eu, "Fernando Pessoa, / plena / é a tua poesia, e a minha / nem sei se valeu a pena", lançando assim a indagação, a dúvida suprimida do título, para o "mundo da poesia", que foi, verdadeiramente, o "mundo" onde sempre habitaram ambos.

Figura 1: Fac-símile de poema manuscrito de Jurandyr Bexerra

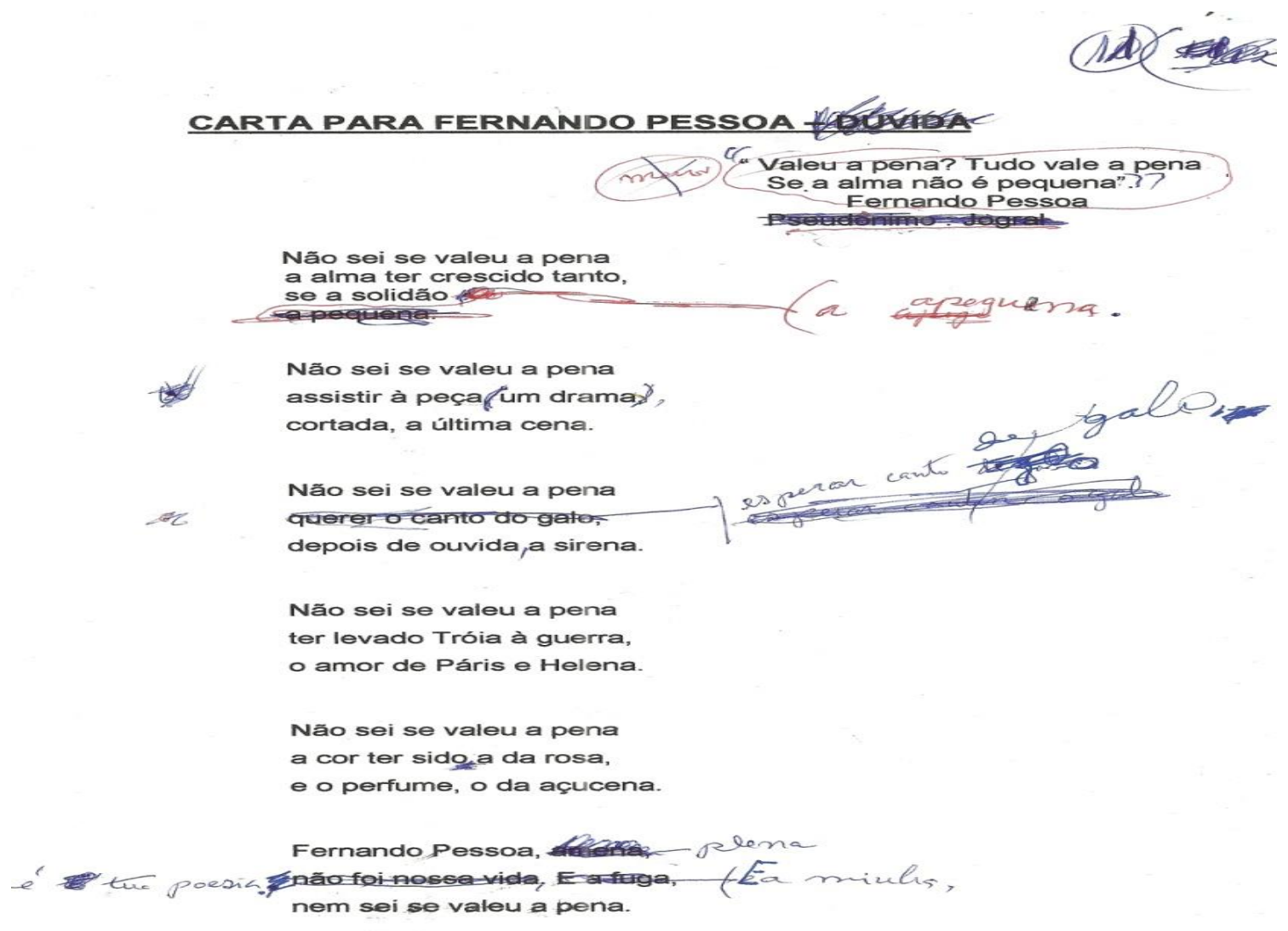

Fonte: Acervo do autor.

Além das mudanças e substituições visíveis no fac-símile do poema, há o "Pseudônimo: Jogral", rasurado. Uma clara alusão ao fato de que esse manuscrito seria enviado a algum certame literário, quer dizer, o poeta em certo momento julgou que o poema "Carta para Fernando Pessoa" estivesse concluído, mas algum tempo depois mudou de ideia. Com efeito, a rasura aponta para a desistência do envio, o Jogral declinou de competir e voltou ao trabalho com a palavra, à reelaboração do poema. 
Sabe-se que as rasuras, nos poemas digitoscritos, frequentemente expressam o movimento dialético que reitera, substitui ou refuta de palavras e imagens. Ou seja, representam adesão e censura nos versos do Jurandyr crítico rigoroso, da própria poesia. Salles assevera que as rasuras "conseguem flagrar e arquivar registros da percepção: são as reservas passionais do artista. Registros que refletem o modo pelo qual aquele artista percebe o mundo" (2009, p. 91). Instaura-se, assim, o ambiente que constitui o trabalho em processo.

Desse modo, o poeta promove um diálogo com os poemas digitoscritos, procurando, numa espécie de segunda (às vezes terceira, quarta ou mais) construção do mesmo poema, encontrar outras possibilidades semânticas, sintáticas, lexicais, soluções e formas dentro do resultado atingido até o momento em que a página fora impressa pela última vez. Seguir a trilha deixada na margem desses papéis é trabalho que possibilita, e legitima, o trabalho crítico de recomposição dos caminhos da criação podendo levar ao melhor entendimento para edição da obra, por meio da interpretação das variantes deixadas nas diferentes versões. Nesse sentido, em Textos impressos e manuscritos, aventa Telê Ancona Lopez:

\footnotetext{
Mesmo no caso das mudanças, o entendimento de um caminho, a análise e a interpretação privilegiando um determinado momento na evolução do projeto literário, autorizam a edição crítica, que lida com manuscritos e textos impressos, a eleger ou a compor uma lição, acatando uma certa versão, ou construindo a própria, mediante o concurso de variantes fundamentais, abonadas por diferentes versões (1996, p. XLIV).
}

No artigo "Discurso e marginalidade", Philippe Willemart afirma que o crítico, no momento em que pretende examinar os processos de criação e o percurso do criador por meio desses documentos, visa, entre outras coisas, compreender como caminha o espírito humano e como ele chega a criar obras de arte. Por essa razão, nada é mais precioso, para o crítico, do que os rascunhos, "[...] que são a manifestação e que desenham o percurso da invenção" (1998, p. 9). Portanto, as rasuras nos manuscritos de Jurandyr são um campo de estudos que traz à tona leituras, preferências, mudanças de procedimentos e diferentes dimensões e perspectivas de criação.

Finalmente, na poesia de Jurandyr Bezerra, palavra e objetos vivem em conjunção, convivem num permanente estado reflexivo. Um renomado crítico, analisando a poética de Bezerra, a partir do único livro publicado até agora, Os limites do pássaro, conclui: 
também uma espécie de pensamento discursivo. Dizia Mallarmé que a força da palavra, sozinha, inventa uma realidade superior. O fazer-poesia, em Os limites do pássaro, apresenta uma visão do universo ao mesmo tempo em que se fixa nos objetos, nas coisas, em tudo que tenha em si a concretude do que existe (OLINTO, 2005).

\section{CONSIDERAÇÕES FINAIS}

Os estudos de manuscritos são importantes no contexto de dar a conhecer certos aspectos da obra em época de seu processo, quando ainda estava distante de parecer acabada. A autoridade desses arranjos antecedentes pode nos guiar pelos labirintos dos processos criativos de escritores, poetas e artistas. Nesse sentido, os documentos do processo criativo reiteram obras finalizadas podendo lançar luz à suas conexões internas e motivos geradores, entre outros aspectos.

Por outro lado, há ainda a relevância dos manuscritos de escritores que pouco ou nada publicaram, deixando obras inéditas em versões manuscritas. Nesse caso, o cuidado de preservação dos documentos e a realização de estudos aprofundados sobre esses materiais urge como única alternativa de dar a conhecer obras por vezes formidáveis e prestes a desaparecer, no tempo e no esquecimento.

Os manuscritos de Jurandyr Bezerra se inserem nessa chave. As análises críticas da construção formal, o efeito estético e a força lírica desses poemas, bem como a excelente recepção crítica, dada ao único livro publicado pelo autor, impõem a necessidade de se estudar e editar de maneira cuidadosa os manuscritos do paraense.

Neste artigo empreendemos um esforço nesse sentido mesmo de dar a conhecer, na exposição da organização de manuscritos e análise de poema, a importância dessa formidável poesia. Se o estado do Pará legou à Amazônia e ao Brasil tantos brilhantes poetas no século XX, como Max Martins, Mário Faustino, Rui Barata, Bruno de Menezes, Antônio Tavernard, João de Jesus Paes Loureiro, entre outros, já é hora de se fazer justiça e buscar retirar Jurandyr Bezerra e sua poesia do ostracismo e também dessa espécie de "limbo" que significa não estar ainda publicada em livro.

\section{REFERÊNCIAS}

ANTONIO CANDIDO. Iniciação a literatura brasileira. Rio de Janeiro: Ouro sobre Azul, 2004.

BEZERRA, Jurandyr. Os limites do pássaro. Belém: Edições Cejup. 1993.

. “Obsessão”. (Crônica inédita). Rio de Janeiro. Data indeterminada. 
indeterminada.

. "Carta para Fernando Pessoa". (Poema inédito). Rio de janeiro. Data

CRUZ, Leonam. Orelha, HAY, Louis. A literatura sai do arquivo: questões de crítica genética. In: BEZERRA, Jurandyr. Os limites do pássaro. Belém: Cejup. 1993. Belo Horizonte: Editora UFMG, 2007.

HAY, Louis. A literatura sai dos arquivos. In: MIRANDA, Wander Mello; SOUZA, Eneida Maria de. (Orgs.) Arquivos literários. Trad. Renato de Mello. São Paulo: Ateliê Editorial, 2003.

LOPEZ, Telê Porto Ancona (Coordenadora). Macunaíma - o herói sem nenhum caráter. Rio de Janeiro: ALLCA XX / UFRJ. Edição Crítica. 1996. p. XLIV.

MAUÉS, Júlia. A modernidade literária no Pará: o Suplemento Literário da Folha do Norte. Belém: UNAMA, 2002.

NUNES, Benedito. Do Marajó ao arquivo - breve panorama da cultura no Pará. Belém: Secult / Ed.Ufpa, 2012.

OLINTO, Antônio. A palavra poética. A tribuna. Rio de Janeiro. 27 de setembro, 2005.

SALLES, Cecília Almeida. Gesto inacabado: processo de criação artística. São Paulo: FAPESP / Annablume. 2009.

. Crítica genética: fundamentos dos estudos genéticos sobre criação artística.

São Paulo: Educ, 2008.

SALLES, Vicente. Memorial da Cabanagem. Belém: Cejup, 1992.

SARGES, Maria Nazaré. Riquezas produzidas na belle époque: Belém do Pará (18701912). Belém: Paka Tatu, 2002.

WILLEMART, Philippe. Discurso e Marginalidade. In: Manuscrítica: Revista de crítica genética, $n^{\circ}$ 7. São Paulo, 1998. Manuscrítica 9.

VIEIRA, Paulo. Roberto. Arte, Erotismo, Natureza e Amizade: Os diários de Max Martins. São Paulo: Intermeios/FAPESP, 2017. 